\title{
Renal carcinoid tumor: An immunohistochemical and molecular genetic study of four cases
}

\author{
NAOTO KURODA ${ }^{1}$, ISABEL ALVARADO-CABRERO ${ }^{2}$, RADEK SIMA $^{3}$, ONDREJ HES ${ }^{3}$, \\ MICHAL MICHAL $^{3}$, HIDEFUMI KINOSHITA ${ }^{4}$, TADASHI MATSUDA ${ }^{4}$, CHISATO OHE $^{5}$, \\ NORIKO SAKAIDA ${ }^{5}$, YOSHIKO UEMURA ${ }^{5}$ and GANG-HONG LEE ${ }^{6}$ \\ ${ }^{1}$ Department of Diagnostic Pathology, Kochi Red Cross Hospital, Kochi 780-8562, Japan; ${ }^{2}$ Department of Pathology, \\ Mexican Oncology Hospital, National Medical Center, 06720 Mexico D.F., Mexico; ${ }^{3}$ Department of Pathology, \\ Charles University Hospital Plzen, 30460 Plzen, Czech Republic; Departments of ${ }^{4}$ Urology, and ${ }^{5}$ Pathology, \\ Kansai Medical University Hirakata Hospital, Osaka 573-1191; ${ }^{6}$ Department of Pathology, \\ Kochi Medical School, Kochi University, Kochi 783-8505, Japan
}

Received August 20, 2009; Accepted October 12, 2009

DOI: $10.3892 /$ ol_00000015

\begin{abstract}
Few genetic studies of renal carcinoid tumor have been conducted thus far. We performed immunohistochemical and genetic examinations on four renal carcinoid tumors. Histologically, the tumors consisted of neoplastic cells with round to oval nuclei. Various growth patterns such as tightly packed cords and trabeculae, ribbon-like, trabecular, sheet-like or solid growth were observed. Nuclear chromatin showed a coarse and granular pattern. Immunohistochemically, tumors were positive for chromogranin A and synaptophysin. In the fluorescence in situ hybridization study, three of four tumors revealed monosomy of chromosome 3 (D3Z1), but one tumor showed monosomy of chromosome 13 (D13S319/13q34). Using PCR amplification and fragment analysis of three microsatellite markers (D3S1300, D3S666 and D3S1768) of chromosome arm 3p, one tumor showed loss of heterozygosity at D3S1300 and D3S1768, one tumor was not informative and the analysis of two tumors failed due to low DNA quality. In three cases, the $V H L$ gene status was tested. Two tumors showed wild-type, but the analysis of one tumor failed to provide adequate results. In conclusion, we suggest that the abnormality of chromosome 3 is involved in the pathogenesis of renal carcinoid tumor.
\end{abstract}

\section{Introduction}

Primary renal carcinoid tumor arising from renal parenchyma or renal pelvis is a rare neoplasm, and approximately 80 cases

Correspondence to: Dr Naoto Kuroda, Department of Diagnostic Pathology, Kochi Red Cross Hospital, Shin-honamchi 2-chome 13-51, Kochi City, Kochi 780-8562, Japan

E-mail: kurochankochi@yahoo.co.jp

Key words: renal carcinoid tumor, fluorescence in situ hybridization, chromosome 3, VHL gene, $3 \mathrm{p} \mathrm{LOH}$ with such a tumor have been reported thus far (1-12). However, few studies report on the genetic characteristics of primary renal carcinoid tumor. Previously, a case of primary renal carcinoid tumor sharing common molecular abnormality with clear cell renal cell carcinoma (RCC) was reported (5). Additionally, the numerical and structural abnormality of chromosome 13 was described in primary renal carcinoid tumor associated with horseshoe kidney (6). This study investigated the status of chromosomes 3 and 13 in four primary renal carcinoid tumors using fluorescence in situ hybridization (FISH), loss of heterozygosity (LOH) of $3 p$ and VHL gene analysis and discussed the pathogenesis.

\section{Materials and methods}

Archive materials. Among pathology files exceeding 14,000 renal tumors originating from Kochi Red Cross Hospital, Japan; Mexico Medical Center, Mexico; Charles University Hospital Plzen, Czech Republic and Kansai Medical University Hirakata Hospital, Japan, four cases with renal carcinoid tumor arising from the renal pelvis (case 1, Tables I and II) or renal parenchyma (cases 2-4, Tables I and II) were selected for the present study. Patient age ranged from 32 to 55 years, and the gender ratio of male to female was 1:3. One patient was previously described (12).

Histological examination and immunohistochemistry. Renal tumor tissues obtained from nephrectomy were fixed in $10 \%$ formalin and embedded in paraffin. Sections (3- $\mu$ m thick) were stained with H\&E. Additionally, immunohistochemical staining was performed using a Histofine Simple Stain-PO (Multi) kit (Nichirei, Tokyo, Japan). Antibodies against chromogranin A (polyclonal; DakoCytomation, Glostrup, Denmark), synaptophysin (polyclonal; DakoCytomation) and CD56 (N-CAM) (123C3, 1:40; Zymed Laboratories, San Francisco, CA, USA) were employed in the present study. Specimens of normal pancreas were used as positive controls of the above described antibodies. 
A

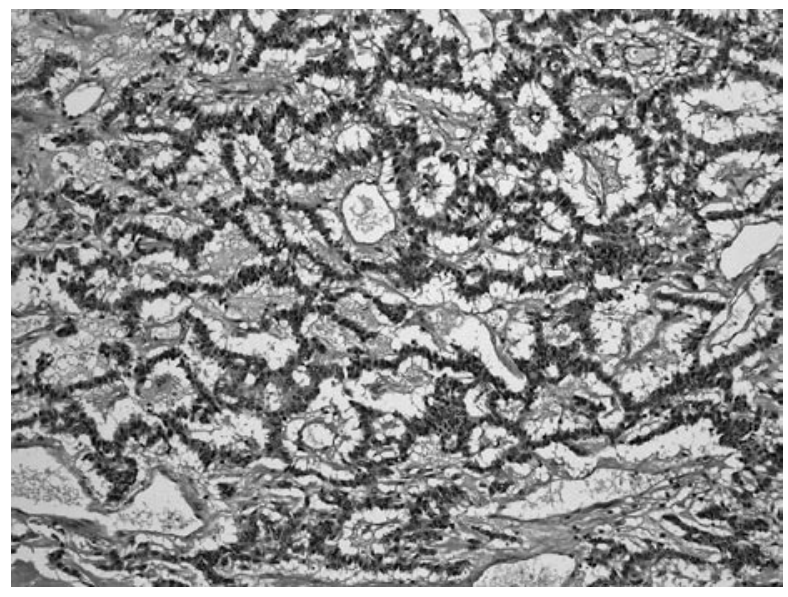

B

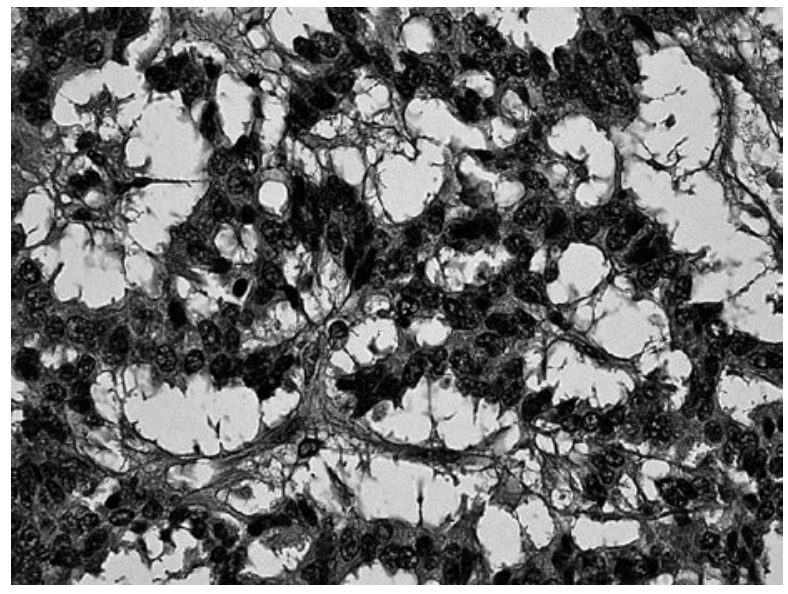

Figure 1. Histological findings of carcinoid tumor. (A) Cuboidal neoplastic cells proliferate in a trabecular pattern. (B) Round nuclei exhibit a coarse granular chromatin pattern, and the cytoplasm shows a eosinophilic staining pattern.

Table I. Immunohistochemical results.

\begin{tabular}{lcccc}
\hline & Case 1 & Case 2 & Case 3 & Case 4 \\
\hline Chromogranin A & $\mathrm{f},+$ & $\mathrm{f},+$ & $\mathrm{d},+$ & $\mathrm{d},+$ \\
Synaptophysin & $\mathrm{f},+$ & $\mathrm{f},+$ & $\mathrm{d},+$ & $\mathrm{d},+$ \\
CD56 & - & $\mathrm{f},+$ & $\mathrm{d},+$ & - \\
\hline
\end{tabular}

d, diffuse; f, focal.

Fluorescence in situ hybridization (FISH). FISH was performed using probes detecting chromosome 3 (D3Z1) and chromosome 13 (D13S319/13q34). FISH was carried out in the Cytogenetic Testing Group, Molecular Genetic Testing Department, Clinical Testing Center, Mitsubishi Chemical Medience Corporation, Kyoto, Japan. In each case, >300 neoplastic cells were counted, and the percentages of one, two and three signals per cell were calculated. The cut-off value for monosomy was judged as $>20 \%$.

Analyses of $3 p \mathrm{LOH}$ and $\mathrm{VHL}$ gene mutation. These analyses were performed in the Department of Pathology, Charles University Hospital Plzen, Czech Republic. Several sections $(10-\mu \mathrm{m}$ thick) were cut from each formalin-fixed, paraffin-embedded block. The tumorous component was microdissected. DNA was extracted by the NucleoSpin Tissue Kit (Macherey Nagel, Duren, Germany) according to the manufacturer's protocol. Polymerase chain reaction (PCR) for $\mathrm{LOH}$ analysis of chromosome $3 p$ was performed. Short tandem repeat markers and primers were as follows: D3S1300 F, AGCTCACATTCTAGTCAGCCT and R, GCCAATTCCCC AGATG; D3S666F, CAAGGCATTAAAGTGGCCACGC and R, GTTTGAACCAGTTTCCTACTGAG; D3S1768 F, GGT TGCTGCCAAAGATTAGA and R, CACTGCATTTGCTGT TGGA. Normal tissues of the same patients were used as a reference. Reaction conditions were as follows: $12.5 \mu \mathrm{l}$ of HotStart Taq PCR Master Mix (Qiagen, Hilden, Germany), $10 \mathrm{pmol}$ of each primer, $100 \mathrm{ng}$ of template DNA, and distilled water up to $25 \mu \mathrm{l}$. The amplification program for the fragments consisted of denaturation at $95^{\circ} \mathrm{C}$ for $15 \mathrm{~min}$, followed by 40 cycles of denaturation at $95^{\circ} \mathrm{C}$ for $1 \mathrm{~min}$, annealing at $55^{\circ} \mathrm{C}$ for $1 \mathrm{~min}$, and extension at $72^{\circ} \mathrm{C}$ for $1 \mathrm{~min}$. The program was completed by incubation at $72^{\circ} \mathrm{C}$ for $7 \mathrm{~min}$. The annealing temperature for fragment D3S666 was $58^{\circ} \mathrm{C}$. Additionally, analysis of three coding exons and exon-intron junctions of the $V H L$ gene was performed by PCR and direct sequencing according to the previously described method (13).

\section{Results}

Microscopic findings. The tumors consisted of neoplastic cells with round to oval nuclei. Various growth patterns such as tightly packed cords and trabeculae, ribbon-like, trabecular (Fig. 1A), sheet-like or solid growth were observed. The cell border was generally indistinct. Nuclear chromatin exhibited a coarse and granular pattern (Fig. 1B). Necrosis or abnormal mitotic figures were absent.

Immunohistochemical findings. Immunohistochemical results are summarized in Table I. Four neoplastic cells were positive for chromogranin A and synaptophysin. The positivity for chromogranin A and synaptophysin in two tumors (cases 3 and 4) was diffuse, and that of the remaining two tumors (cases 1 and 2) was focal. Neoplastic cells were positive for CD56 in two tumors. The positivity of one tumor (case 3) was diffuse, while that of the other (case 2) was focal.

FISH findings. The results of the FISH analysis are summarized in Table II. Tumorous cells of cases 1, 2 and 3 exhibited monosomy of chromosome 3 (Fig. 2), but one tumor (case 4) showed disomy of chromosome 3 . In case 1 , neoplastic cells demonstrated a monosomy of chromosome 13 , but tumorous cells in cases 2, 3 and 4 showed a disomy of chromosome 13.

Findings of $3 p \mathrm{LOH}$ and $\mathrm{VHL}$ gene mutation analyses. The results are summarized in Table II. Regarding 3p LOH, one tumor showed LOH at two (D3S1300 and D3S1768) of three loci tested. One tumor was not informative, and two tumors failed to provide better results due to low DNA quality. Concerning VHL gene analysis, two tumors showed wild-type 
Table II. Results of fluorescence in situ hybridization, 3p LOH and VHL gene mutation analyses.

\begin{tabular}{|c|c|c|c|c|c|c|}
\hline & Chromosome 3 & Chromosome 13 & D3S 1300 & D3S666 & D3S1768 & VHL gene mutation \\
\hline Case 1 & Monosomy & Monosomy & \multirow{5}{*}{ Failed } & \multirow{5}{*}{ Failed } & \multirow{5}{*}{ Failed } & \multirow{5}{*}{ Failed } \\
\hline Total cells & 507 & 599 & & & & \\
\hline One signal & $261(51.5 \%)$ & $403(67.3 \%)$ & & & & \\
\hline Two signals & $226(44.6 \%)$ & $196(32.7 \%)$ & & & & \\
\hline Three signals & $20 \quad(3.9 \%)$ & $0 \quad(0 \%)$ & & & & \\
\hline Case 2 & Monosomy & Disomy & \multirow{5}{*}{ Negative } & \multirow{5}{*}{ Negative } & \multirow{5}{*}{ Negative } & \multirow{5}{*}{ Not performed } \\
\hline Total cells & 518 & 512 & & & & \\
\hline One signal & $404(78.0 \%)$ & $85(16.6 \%)$ & & & & \\
\hline Two signals & $112(21.6 \%)$ & $417(81.4 \%)$ & & & & \\
\hline Three signals & $2(0.2 \%)$ & $10(2.0 \%)$ & & & & \\
\hline Case 3 & Monosomy & Disomy & \multirow{5}{*}{$\mathrm{LOH}$} & \multirow{5}{*}{ Negative } & \multirow{5}{*}{$\mathrm{LOH}$} & \multirow{5}{*}{ Wild-type } \\
\hline Total cells & 617 & 541 & & & & \\
\hline One signal & $577(93.5 \%)$ & $29 \quad(5.4 \%)$ & & & & \\
\hline Two signals & $37 \quad(6.0 \%)$ & $492(90.9 \%)$ & & & & \\
\hline Three signals & $3(9.5 \%)$ & $20 \quad(3.7 \%)$ & & & & \\
\hline Case 4 & Disomy & Disomy & \multirow{5}{*}{ Failed } & \multirow{5}{*}{ Failed } & \multirow{5}{*}{ Failed } & \multirow{5}{*}{ Wild-type } \\
\hline Total cells & 366 & 334 & & & & \\
\hline One signal & $43(11.7 \%)$ & $27 \quad(8.1 \%)$ & & & & \\
\hline Two signals & $317(86.6 \%)$ & $303(90.7 \%)$ & & & & \\
\hline Three signals & $6(1.6 \%)$ & $4(1.2 \%)$ & & & & \\
\hline
\end{tabular}

Failure was due to low DNA quality. LOH, loss of heterozygosity.

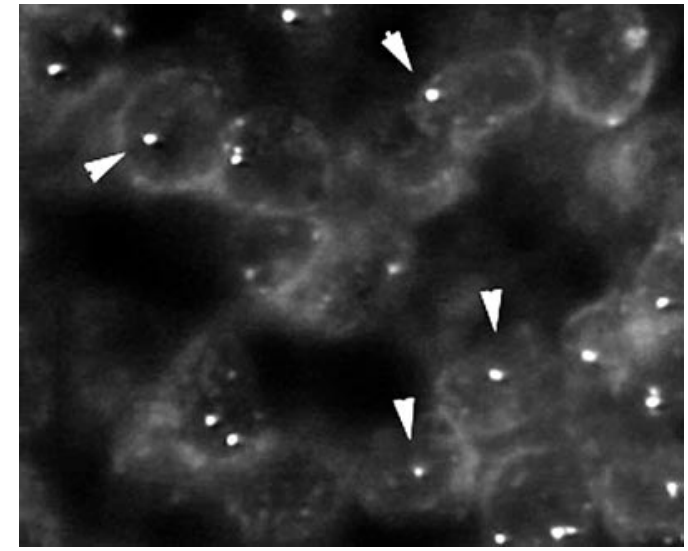

Figure 2. Results of fluorescence in situ hybridization (FISH). Many neoplastic cells exhibit monosomy of chromosome 3 .

and one tumor failed due to low DNA quality. In one case, VHL gene analysis was not performed (Fig. 3).

\section{Discussion}

Primary renal carcinoid tumor is a rare neoplasm, and approximately 80 cases with such a tumor have been previously reported. This tumor frequently occurs in patients $<50$ years of age, affects male and female patients with equal frequency and does not appear to present with carcinoid syndrome (11). It is well known that primary renal carcinoid tumor is associated

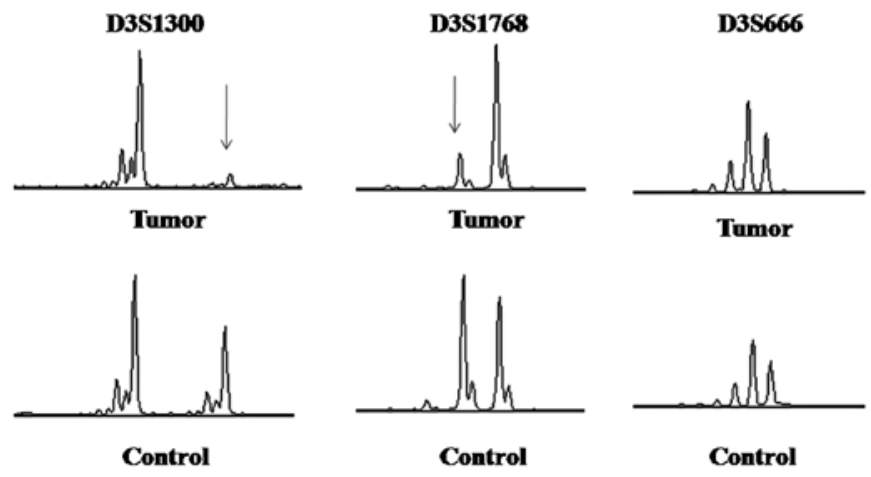

Figure 3. Results of 3p loss of heterozygosity (LOH) analysis. Arrow indicates loss of one allele in tumor DNA in comparison with control (non-neoplastic) DNA, using microsatellite markers D3S1300 and D3S1768.

with other renal diseases including horseshoe kidney (17.8\%), teratoma $(14.3 \%)$ or polycystic kidney disease $(1.8 \%)(6-10)$. However, no tumors in the present study were associated with any other renal diseases. Poor patient prognostic factors include an age $>40$ years, tumor size $>4 \mathrm{~cm}$, a purely solid tumor on the cut surface, a mitotic rate $>1 / 10$ high power fields, metastases at initial diagnosis and tumors extending into the extrarenal tissue (9). Patients with this tumor often present with regional lymph node metastases which may progress to distant organ metastases, but usually pursue a prolonged clinical course despite widely metastastic disease 
(11). Accordingly, it is very important for surgical pathologists to accurately recognize and diagnose renal carcinoid tumors due to their peculiar clinical behavior.

Genetic studies of renal carcinoid tumor are currently limited $(5,6)$. In the present study, three of four tumors (75\%) demonstrated monosomy of chromosome 3 by FISH analysis. Therefore, we suggest that the numerical loss of chromosome 3 plays a crucial role in the pathogenesis of primary renal carcinoid tumor. Previous cytogenetic studies of carcinoid tumor of the respiratory area failed to show any abnormalities of chromosome $3(14,15)$. Therefore, it is possible that renal carcinoid tumor is genetically different from respiratory carcinoid tumor. On the other hand, primary renal carcinoid tumor showing the abnormality of chromosome 3, characteristic of clear cell RCC, was previously reported (5). In pulmonary carcinoid tumor, Hurr et al (16) failed to detect any $3 p$ deletion, and some investigators detected allelic loss at a limited loci of small number $(17,18)$. From the results of the present study, we can infer that $\mathrm{LOH}$ of chromosome $3 p$ is involved in the pathogenesis of certain cases of renal carcinoid tumors. A large scale study is necessary to clarify the frequency and significance of $3 \mathrm{p} \mathrm{LOH}$ in renal carcinoid tumor. However, it is unlikely that the $V H L$ gene is associated with the pathogenesis of renal carcinoid tumor. This suggests that renal carcinoid tumors do not differentiate from clear cell RCC or that both tumors do not originate from common stem cells. Additionally, only one of the four tumors $(25 \%)$ showed monosomy of chromosome 13 by FISH analysis. The abnormality of chromosome 13 by G-band karyotype has been reported in gastric carcinoid tumor (19). Although Van den Berg et al (6) detected the numerical and structural abnormality of chromosome 13 by a G-band karyotype, a numerical abnormality of chromosome 13 in renal carcinoid tumor appears to occasionally occur on the basis of our results. The rate $(25 \%)$ of abnormality of chromosome 13 in renal carcinoid tumor using FISH analysis appears to be comparable with the rate $(17 \%)$ of abnormality of chromosome 13 in carcinoid tumor of various anatomic sites using genome-wide single nucleotide polymorphism analysis (20).

In conclusion, the abnormality of chromosome 3 may be involved in the pathogenesis of some cases of renal carcinoid tumor.

\section{Acknowledgements}

The authors are grateful to the Cytogenetic Testing Group, Molecular Genetic Testing Department, Clinical Testing Center, Mitsubishi Chemical Medience Corporation, Kyoto, Japan for their technical assistance.

\section{References}

1. Toker C: Carcinoidal renal tumor. J Urol 111: 10-11, 1974.

2. Stahl RE and Sidhu GS: Primary carcinoid tumor of the kidney. Light and electron microscopic study. Cancer 44: 1345-1349, 1974.
3. Ji X and Li W: Primary carcinoid of renal pelvis. J Environ Pathol Toxicol Oncol 13: 269-271, 1994.

4. Rudrick B, Nguyen GK and Lakey WH: Carcinoid tumor of the renal pelvis: report of a case with positive urine cytology. Diagn Cytopathol 12: 360-363, 1995.

5. El-Naggar AK, Troncoso P and Ordonez NG: Primary renal carcinoid tumor with molecular abnormality characteristic of conventional renal cell neoplasms. Diagn Mol Pathol 4: 48-53, 1995.

6. Van den Berg E, Gouw A, Oosterhuis JW, Störkel S, Dijkhuizen T, Mensink HJ and de Jong B: Carcinoid in a horseshoe kidney. Morphology, immunohistochemistry and cytogenetics. Cancer Genet Cytogenet 84: 95-98, 1995.

7. Krishnan B, Truong LD, Saleh G, Sirbasku M and Slawin KM: Horseshoe kidney is associated with an increased relative risk of primary carcinoid tumor. J Urol 157: 2059-2066, 1997.

8. Yoo J, Park S, Lee HJ, Kang SJ and Kim BK: Primary carcinoid tumor arising in a mature teratoma of the kidney. A case report and review of the literature. Arch Pathol Lab Med 126: 979-981, 2002.

9. Romero FR, Rais-Bahrami S, Permpongkosol S, Fine SW, Kohanim S and Jarrett TW: Primary carcinoid tumor of the kidney. J Urol 176: 2359-2366, 2006.

10. Murali R, Kneale K, Lalak N and Delprado W: Carcinoid tumors of the urinary tract and prostate. Arch Pathol Lab Med 130: 1693-1706, 2006

11. Hansel DE, Epstein JI, Berbescu E, Fine SW, Young RH and Cheville JC: Renal carcinoid tumor: a clinicopathologic study of 21 cases. Am J Surg Pathol 31: 1539-1544, 2007.

12. Kuroda N, Tamura M, Hes O, Michal M, Hayashi Y and Lee GH: Carcinoid tumor of renal pelvis: consideration on the histogenesis. Pathol Int 58: 51-54, 2008.

13. Michal M, Hes O, Nemcova J, Sima R, Kuroda N, Bulimbasic S, Franco M, Sakaida N, Danis D, Kazakov DV, Ohe C and Hora M: Renal angiomyoadenomatous tumor: morphologic, immunohistochemical and molecular genetic study of a distinct entity. Virchows Arch 454: 89-99, 2009.

14. Teyssier JR, Sadrin R, Nou JM, Bureau G, Adnet JJ, Bajolle F and Pigeon F: Trisomy 7 in a lung carcinoid tumor. Precocious index of malignant transformation? Cancer Genet Cytogenet 15: 277-282, 1985.

15. Johansson M, Hein S, Mandahl N, Hambraeus G, Johansson L and Mitelman F: Cytogenetic analysis of six bronchial carcinoids. Cancer Genet Cytogenet 66: 33-38, 1993.

16. Hurr K, Kemp B, Silver SA and El-Naggar AK: Microsattelite alteration at chromosome $3 \mathrm{p}$ loci in neuroendocrine and nonneuroendocrine lung tumors. Am J Pathol 149: 613-620, 1996.

17. Kovatich A, Friedland DM, Druck T, Hadaczek P, Huebner K, Comis RL, Hauck W and McCue PA: Molecular alterations to human chromosome $3 \mathrm{p}$ loci in neuroendocrine lung tumors. Cancer 83: 1109-1117, 1998.

18. Onuki N, Wistuba II, Travis W, Virmani AK, Yashima K, Brambilla E, Hasleton P and Gazdar AF: Genetic changes in the spectrum of neuroendocrine lung tumors. Cancer 85: 600-607, 1999.

19. Panani AD, Malliaros S, Ferti A and Raptis S: Cytogenetic study of a malignant carcinoid tumor. Cancer Genet Cytogenet 59: 220, 1992.

20. Kim DH, Nagano Y, Choi IS, White JA, Yao JC and Rashid A: Allelic alterations in well-differentiated neuroendocrine tumors (carcinoid tumors) identified by genome-wide single nucleotide polymorphism analysis and comparison with pancreatic endocrine tumors. Genes Chromosomes Cancer 47: 84-92, 2008. 